\title{
KERAGAMAN SUBSTRAT BAGI NUDIBRANCH DI SELAT LEMBEH
}

\author{
(Substrate diversity of nudibranch at Lembeh Strait)
}

Yehezkiel S.P.H. Marpaung ${ }^{1 *}$, Medy Ompi ${ }^{1}$, Indri Manembu ${ }^{1}$, Kakaskasen A. Roeroe ${ }^{1}$, N.G.F. Mamangkey ${ }^{1}$, Lucky Lumingas ${ }^{2}$

1. Program Studi Ilmu Kelautan, Fakultas Perikanan dan Ilmu Kelautan, Universitas Sam Ratulangi, Manado. 95115, Sulawesi Utara, Indonesia.

2. Program Studi Manajemen Sumberdaya Perairan, Fakultas Perikanan dan IImu Kelautan, Universitas Sam Ratulangi, Manado. 95115, Sulawesi Utara, Indonesia.

*email: marpaunghezky11@gmail.com

Research on the diversity of nudibranch substrates was carried out in Lembeh Strait at 3 locations, at Nudifall, Makawide, and Nudiritrit. The purpose of the researchs 1) to discover the nudibranch species at Nudifall, Makawide, Nudiritrit in the Lembeh Strait. 2) to knowing the substrate occupied by nudibranchs in the Lembeh Strait. 3) to knowing the overlapping substrate that was occupied by the nudibranch. Subtrates can to be used by nudibranches to get food sources, shelter from predators, and as a place to live. Nudibranch species found in the Lembeh Strait were 19 species in this study. Dead Coral with Algae (DCA), sponges, algae, hard coral, and tunicates were the types of substrate where nudibranches live in the Lembeh Strait The most dominant or overlapping substrate between types of nudibranchs was Dead Coral with Algae.

Keywords : Nudibranch, Substrate, Lembeh

Penelitian mengenai keragaman substrat nudibranch dilakukan di Selat Lembeh pada 3 lokasi yaitu Nudifall, Makawide, dan Nudiritrit. Tujuannya yaitu 1) mengetahui jen nudibranch di Nudifall, Makawide, Nudiritrit di Selat Lembeh. 2) mengetahui substrat yang ditempati nudibranch di Selat Lembeh. 3) mengetahui substrat yang tumpang tindih (overlap) yang ditempati oleh nudibranch. Subtrat dapat dimanfaatkan oleh nudibranch untuk mendapatkan sumber makanan, tempat berlindung dari predator, dan sebagai tempat tinggal. Jenis nudibranch yang ditemukan di Selat Lembeh ada 19 spesies dalam penelitian ini. Dead Coral with Algae (DCA), spons, alga, hard coral, dan tunikata merupakan substrat-substrat tempat hidup nudibranch di Selat Lembeh. Substrat yang paling dominan atau tumpang tindih antar jenis dari nudibranch adalah DCA.

Kata kunci : Nudibranch, Substrat, Lembeh.

\section{PENDAHULUAN}

Nudibranch adalah kelompok gastropoda yang sangat dikenal oleh para penyelam dan menjadi salah satu target foto objek bawah laut. Biota dasar ini memiliki ragam ukuran bentuk dan warna sehingga menjadi sangat menarik untuk dilihat di bawah air bagi para penyelam. Nudibranch berasal dari kata "nudus" berarti 
telanjang dan "branchia" yang berarti insang, jika kedua kata ini digabungkan berarti insang telanjang. Bell \& Galzin (1984) menyebutkan dalam penelitiannya bahwa, terdapat hubungan langsung antara keragaman substrat dan keanekaragaman jenis organisme bentik. Di duga bahwa substrat yang semakin beragam, maka makin banyak jumlah nudibranch dan makin baik keanekaragaman jenis.

Di seluruh dunia telah telah teridentifikasi \pm 3000 spesies nudibranch. Distribusinya juga dapat dipengaruhi pada fase larva, avertebrata tropis dapat memijah dan larvanya tersedia sepanjang tahun termasuk nudibranch (Purba et al, 2013). Substrat bagi nudibranch banyak ditemui di daerah terumbu karang seperti alga, spons, karang keras, karang lunak, bryozoa dan hydroid. Namun demikian sebagai biota bentik, biota ini sangat tergantung pada substrat tidak hanya sebagai tempat menempel ataupun tempat tinggal, tetapi juga sebagai sumber makanan mereka (Kaligis et al, 2018).

Keragaman substrat adalah sebagai salah satu fenomena dasar laut yang mendukung keanekaragaman biota dasar, jika berkurangnya keragaman substrat, bahkan kehilangan substrat karena peningkatan aktifitas pembangunan di pesisir tidak hanya akan menentukan keragaman bahkan keberlanjutan kehidupan biota dasar ini (Greene et al, 2008; Chavanich et al, 2013).

Nudibranch merupakan salah satu kekayaan hayati Indonesia dan harus dijaga kelestariannya. Walaupun biota ini sangat terkenal sebagai target foto bawah laut, serta mengandung komposisi bioaktif, namun informasi mengenai organisme ini masih terbilang sedikit khususnya di Sulawesi Utara. Biota inipun sangat sulit ditemukan karena ukurannya kecil, memiliki kemampuan kamuflase, dan menempel atau yang dikenal sebagai kriptik (Chavanich et al, 2013).

Karakteristik nudibranch yang membedakannya dengan gastropoda lain yaitu adanya insang telanjang (nudibranch berarti 'insang telanjang'). Insang tersebut muncul seperti jambul pada bagian punggung agak ke belakang (Debelius, 2004). Nudibranch memiliki mata yang mungil yang keberadaannya sangat sedikit dimanfaatkan. Mata nudibranch hanya mampu membedakan antara terang dan gelap. Sebagai gantinya, nudibranch menggunakan tonjolan sensor di kepala (rhinopore) dan tentakel oral untuk mencium, mengecap dan merasakan lingkungan. Bahkan rhinopore digunakan untuk mendeteksi makanan dengan bantuan sinyal yang ditangkap dari senyawa kimia (Holland, 2008). Secara garis besar tubuh nudibranch terdiri dari mantel, rhinopores, insang, kaki, dan organ reproduksi

Beragam biota dapat menetap dan tinggal pada substrat yang beragam dari lumpur, pasir, batuan, pecahan karang, dan karang. Umumnya pada substrat tersebut dapat ditemukan biota-biota dasar seperti Bryozoa, Ascidiacea, Crinoidea, Ophiuroidea, dan Polychaeta, termasuk beberapa jenis nudibranch seperti yang dilaporkan di perairan Bunaken (Kaligis et al, 2018). Seperti dasar perairan lainnya hydroid, ascidian, tunikata, dan jenis-jenis nudibranch dapat menempel pada karang dan juga pecahan-pecahan karang (Chavanich et al, 2013).

Dalam penelitian mengangkat rumusan masalah yaitu; 1) jenis nudibranch apa yang ada di Selat Lembeh, 2) substrat apa saja yang ditempati oleh nudibranch, 3) adakah substrat yang tumpang tindih (overlap) yang ditempati oleh nudibranch. 
Untuk tujuan yaitu; 1) mengetahui jenis nudibranch di Nudifall, Makawide, Nudiritrit di Selat Lembeh. 2) mengetahui substrat yang ditempati nudibranch di Selat Lembeh. 3) mengetahui substrat yang tumpang tindih (overlap) yang ditempati oleh nudibranch.

\section{Metode Penelitian}

Penelitian ini dilakukan di Selat Lembeh pada 3 lokasi yaitu Nudifall ( $\mathrm{N} 01^{\circ} 27^{\prime} 674^{\prime \prime}$, E $\left.125^{0} 13^{\prime} 602^{\prime \prime}\right)$, Makawide (N 01028'510", E $\left.125^{0} 14^{\prime} 190^{\prime \prime}\right)$, dan Nudiritrit (N 01029'093", E 125014'459"). Pada lokasi Nudifall topografinya seperti tebing lalu slope mengarah ke laut, lokasi Makawide seperti pulau timbul dengan topografi slope ke arah laut, dan lokasi Nudiritrit sama seperti lokasi Nudifall berbentuk tebing lalu slope ke arah laut.

Selat Lembeh memiliki panjang $\pm 21 \mathrm{~km}$ dan lebar bervariasi dari 1 sampai $2 \mathrm{~km}$
(Ompi et al, 2019). Massa air selat ini sangat dipengaruhi oleh pasang surut, $\mathrm{Di}$ mana adanya masa air yang masuk dari utara dan di buang ke arah selatan, dan juga yang masuk dari selatan dan dibuang ke arah utara sangat menentukan kondisi Selat Lembeh termasuk substrat di dasar selat. Selat ini ditutupi oleh substrat baik lumpur, pasir, rubble, batuan, dan karang. Di mana substrat diameter halus mendominasi perairan ini yang membuat selat ini dikenal sebagai daerah 'muck diving' (Ompi et al, 2019). Substrat halus termasuk biogenik substrat yang menutupi dasar selat lembeh menggambarkan bahwa erosi yang diakibatkan oleh baik arus dan gelombang (Dai et al, 1992) adalah sangat mendominasi perairan ini.

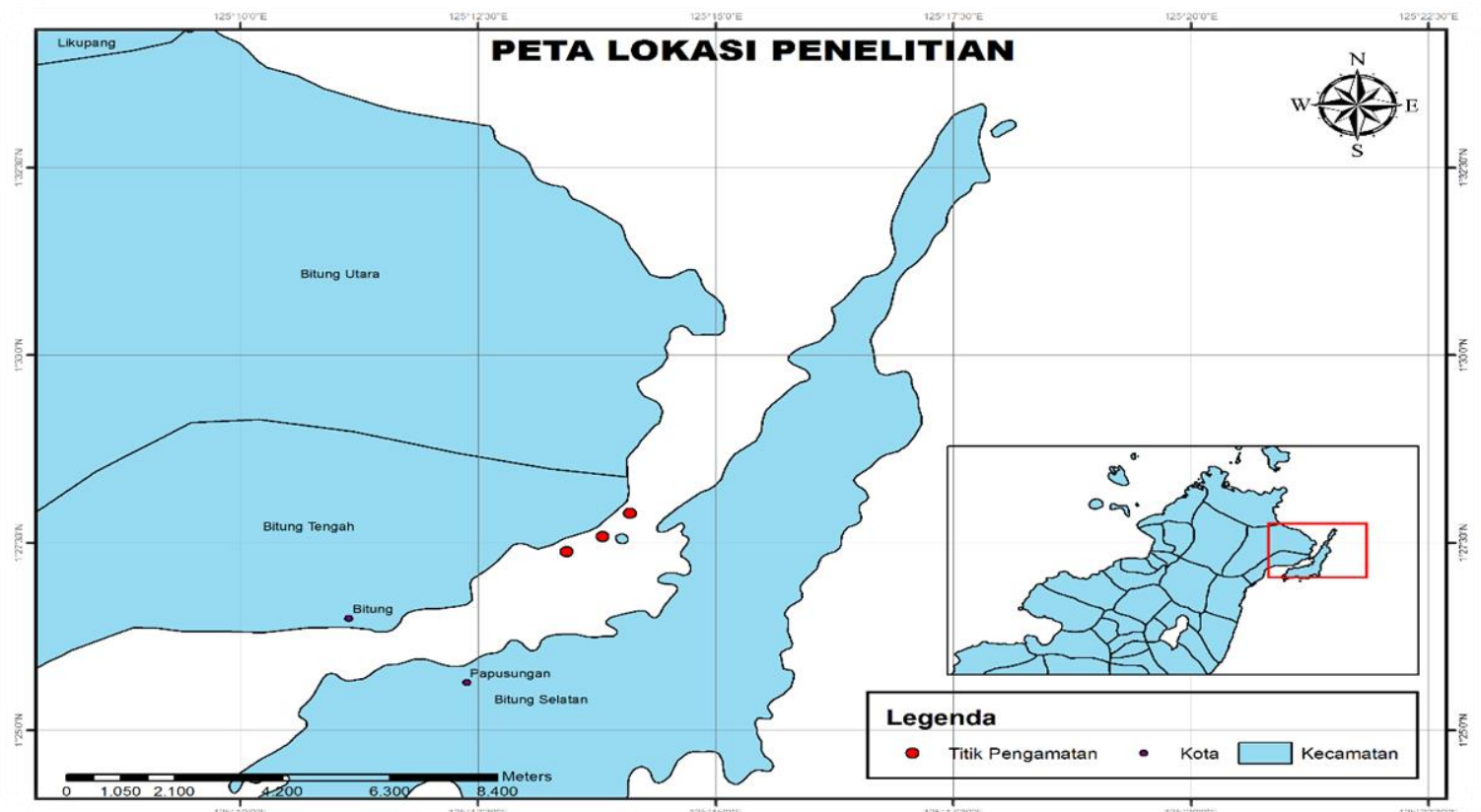

Gambar 1. Peta Lokasi

Pengambilan data dilakukan menggunakaan belt transect dengan panjang $70 \mathrm{~m}$ dan lebar $2 \mathrm{~m}$ (luas $140 \mathrm{~m}^{2}$ ). Tim penyelam menyusuri perairan pantai dengan kedalaman 3-12 meter. Kemudian menarik belt transect sejajar garis pantai. Peletakan transect disesuaikan dengn topografi lokasi pengambilan data. 
Penyelam akan menyusuri belt transect dan mengamati adanya kehadiran nudibranch lalu mendokumentasikannya beserta substrat.

Identifikasi jenis nudibranch dan tipe substrat dilakukan langsung saat pengambilan data serta pengambilan foto yang dilanjutkan dengan melihat hasil foto bawah air. Identifikasi nudibranch dilakukan mulai dari famili, genus, hingga spesies dengan melihat warna pada notum, rhinopore, insang, kaki, dan ukuran tubuh, dengan bantuan beberapa buku identifikasi.

Dalam proses analisis untuk menentukan dominasi substrat pada nudibranch, data yang diperoleh berupa jenis dan jumlah telah ditempat dalam bentuk tabel, di mana dilakukan perhitungan baik jumlah jenis dan individu. Tipe substrat yang ditempati oleh nudibranch termasuk persentase substrat yang ditempati jenis nudibranch juga di petakan dalam tabel dan gambar. Sehingga dapat dilihat dominasi substrat pada nudibranch di Selat Lembeh.

Jenis-jenis substrat diplot ke dalam diagram venn untuk melihat kehadiran jenisjenis yang memanfaatkan substrat yang sama (overlap), serta yang memanfaatkan substrat tersendiri. Pengelompokan kesamaan substrat antar spesies pada penelitian ini menggunakan Cluster analysis yang disajikan dalam bentuk dendogram. Dalam analisis ini data setiap jenis spesies beserta substrat dilihat kemiripannya dengan menggunakan bantuan aplikasi Biodiversity Pro 2.0.

\section{Hasil dan Pembahasan}

Nudibranch yang diidentifikasi di Nudifall ada 11 jenis dengan total 16 individu, Makawide ada 8 jenis dengan total juga 16 individu, dan 8 jenis dengan total 11 individu di Nudiritrit (Tabel 1). Secara keseluruhan, nudibranch yang ditemukan di ketiga lokasi dalam penelitian ini ada 19 jenis dengan total ada 43 individu (Tabel 1). Jumlah jenis Nudibranch di Nudifall lebih tinggi dibandingkan yang diidentifikasi di Makawide dan Nudiritrit yang jumlah jenisnya sama. Perbedaan jenis ini dapat disebabkan oleh kondisi lingkungan lokasi penelitian, di mana Nudifall berada di bagian dalam selat Lembeh, lebih terlindung dibandingkan dengan Makawide dan Nudiritrit yang lebih ke arah utara selat dengan kondisi lingkungan lebih terbuka terhadap arus dan gelombang.

Kondisi lingkungan terlindung dapat menjadi lokasi yang baik terutama bagi umumnya biota avertebrata dasar yang memiliki fase larva. Larva avertebrata laut, seperti juga nudibranch akan berada di kolom perairan dan dalam mengakhiri fase larva akan turun ke dasar (Ompi et al 2019), di mana dengan kondisi terlindung dari arus, larva akan mudah turun ke dasar memilih substrat kesukaan, menempel dan menetap pada substrat yang disukainya. Larva avertebrata tidak seperti larva ikan dan krustasea yang memiliki kecepatan renang yang dapat mengatur arah dan melawan arus dengan kecepatan yang dapat dijangkau. Larva avertebrata moluska termasuk gastropoda, nudibranch umunya berenang pasif, sehingga akan selalu terbawa mengikuti arus, termasuk di perairan yang mengarah ke utara Selat Lembeh, sehingga larva-larva akan mengalami tantangan yang besar untuk turun dan mendapatkan substrat kesukaan di kedua lokasi baik Makawide dan Nudiritrit yang dapat menyebabkan adanya perbedaan jumlah jenis dibandingkan dengan di Nudifall. 
Tabel 1. Nudibranch yang ditemukan di Selat lembeh

\begin{tabular}{|c|c|c|c|c|}
\hline \multirow{2}{*}{ Spesies } & \multicolumn{3}{|c|}{ Site } & \multirow{2}{*}{$\begin{array}{l}\text { Jumlah } \\
\text { individu }\end{array}$} \\
\hline & Nudifall & Makawide & Nudiritrit & \\
\hline Chromodoris annae Bergh, 1877 & 2 & - & 1 & 3 \\
\hline Chromodoris hamiltoni Rudman, 1977 & 1 & 1 & - & 2 \\
\hline Chromodoris lochi Rudman, 1982 & - & - & 1 & 1 \\
\hline Aegires villosus Farran, 1905 & - & 1 & - & 1 \\
\hline Jorunna funnebris (Kelaart, 1859) & - & 1 & - & 1 \\
\hline Glossodoris cincta (Bergh, 1888) & - & - & 2 & 2 \\
\hline Goniobranchus fidelis (Kelaart, 1858) & 2 & - & - & 2 \\
\hline Goniobranchus geometricus (Risbec, 1928) & 1 & - & 1 & 2 \\
\hline $\begin{array}{l}\text { Goniobranchus reticulatus (Quoy \& } \\
\text { Gaimard,1832) }\end{array}$ & - & 2 & - & 2 \\
\hline Hypselodoris tryoni (Garett, 1873) & 2 & - & - & 1 \\
\hline Halgerda batangas Carlson \& Hoff, 2000 & 2 & - & - & 2 \\
\hline Nembrotha kubaryana Bergh, 1877 & 2 & - & - & 2 \\
\hline Flabellina rubrolineata (O’Donoghue, 1929) & 1 & - & - & 1 \\
\hline Flabelina exoptata Gosliner \& Willian, 1991 & - & - & 1 & 1 \\
\hline Phyllidia elegans Berg, 1869 & 1 & - & - & 1 \\
\hline Phyllidia ocellata Cuvier, 1804 & 1 & 4 & 2 & 7 \\
\hline Phyllidiella varicosa (Lamarck, 1801) & 1 & 2 & 2 & 5 \\
\hline Phyllidia coelestis Berg, 1905 & - & 1 & - & 1 \\
\hline Phyllidiella lizae Brunckhorst, 1993 & - & 4 & 1 & 5 \\
\hline Jumlah & 16 & 16 & 11 & 43 \\
\hline
\end{tabular}

Ragam substrat yang teridentifikasi menjadi tempat menempel nudibranch ada 5 tipe substrat, yaitu dead coral with alga/DCA, sponge, alga, hard coral dan tunikata. Dalam penelitian ini ditemukan ada jenis nudibranch yang memiliki substrat yang sama dengan jenis yang lain dan juga ada substrat yang merupakan substrat yang paling dominan ditempati oleh nudibranch.

Substrat dead coral with alga (DCA) mendominasi lokasi Nudifall dengan persentase $68,75 \%$ selanjutnya substrat alga dan tunikata masing-masing memiliki persentase $12,5 \%$ kemudian substrat sponge dengan persentase 6,25\% (Tabel
2). Pada lokasi ini tidak didapati kehadiran nudibranch pada substrat hard coral. Berikut adalah tipe-tipe substrat yang didapati adanya kehadiran nudibranch di lokasi Nudifall.

Pada lokasi Makawide, substrat dead coral with alga (DCA) mendominasi dengan persentase $56 \%$ selanjutnya substrat sponge dan alga masing-masing memiliki persentase $18,75 \%$ kemudian substrat hard coral dengan persentase 6,25\% (Tabel 3). Pada lokasi ini tidak didapati kehadiran nudibranch pada substrat tunikata. Berikut adalah tipe-tipe substrat yang didapati 
adanya kehadiran nudibranch di lokasi Makawide:

Tabel 2. Substrat nudibranch di lokasi Nudifall

\begin{tabular}{lccccc}
\hline \multicolumn{1}{c}{ Spesies } & $\begin{array}{c}\text { Dead Coral } \\
\text { with Alga }\end{array}$ & Sponge & Alga & $\begin{array}{c}\text { Hard } \\
\text { Coral }\end{array}$ & Tunikata \\
\hline Chromodoris annae & 1 & - & 1 & - & - \\
Chromodoris hamiltoni & - & 1 & - & - & - \\
Goniobranchus fidelis & 2 & - & - & - & - \\
Goniobranchus & - & - & 1 & - & - \\
geometricus & 2 & - & - & - & - \\
Hypselodoris tryoni & 2 & - & - & - & - \\
Halgerda batangas & - & - & - & - & 2 \\
Nembrotha kubaryana & 1 & - & - & - & - \\
Flabellina rubrolineata & 1 & - & - & - & - \\
Phyllidia elegans & 1 & - & - & - & - \\
Phyllidia ocellata & 1 & - & - & - & - \\
Phyllidiella varicose & 11 & 1 & 2 & - & 2 \\
\hline Jumlah & $68,75 \%$ & $6,25 \%$ & $12,5 \%$ & - & $12,5 \%$ \\
\hline Persentase & & & & & \\
\hline
\end{tabular}

Tabel 3. Substrat nudibranch di lokasi Makawide

\begin{tabular}{lccccc}
\hline \multicolumn{1}{c}{ Spesies } & $\begin{array}{c}\text { Dead Coral } \\
\text { with Alga }\end{array}$ & Sponge & Alga & $\begin{array}{c}\text { Hard } \\
\text { Coral }\end{array}$ & Tunikata \\
\hline $\begin{array}{l}\text { Chromodoris hamiltoni } \\
\text { Aegires villosus }\end{array}$ & - & 1 & - & - & - \\
$\begin{array}{l}\text { Jorunna funnebris } \\
\text { Goniobranchus }\end{array}$ & - & - & 1 & - & - \\
reticulatus & - & - & - & 1 & - \\
$\begin{array}{l}\text { Phyllidia ocellata } \\
\text { Phyllidiella varicosa }\end{array}$ & 3 & 1 & 2 & - & - \\
$\begin{array}{l}\text { Phyllidia coelestis } \\
\text { Phyllidiella lizae }\end{array}$ & 1 & 1 & - & - & - \\
\hline Jumlah & 4 & - & - & - & - \\
\hline Persentase & 9 & 3 & 3 & 1 & - \\
\hline
\end{tabular}


Substrat dead coral with alga (DCA) juga mendominasi di lokasi Nudiritrit dengan persentase $72,72 \%$, substrat alga memiliki persentase $18,18 \%$ kemudian substrat sponge dengan persentase 9,1\% (Tabel 4).
Pada lokasi ini tidak didapati kehadiran nudibranch pada substrat hard coral dan tunikata. Berikut adalah tipe-tipe substrat yang didapati adanya kehadiran nudibranch di lokasi Nudiritrit:

Tabel 4. Substrat Nudibranch di lokasi Nudiritrit

\begin{tabular}{cccccc}
\hline Spesies & $\begin{array}{c}\text { Dead Coral } \\
\text { with Alga }\end{array}$ & Sponge & Alga & $\begin{array}{c}\text { Hard } \\
\text { Coral }\end{array}$ & Tunikata \\
\hline Chromodoris annae & 1 & - & - & - & - \\
Chromodoris lochi & - & - & 1 & - & - \\
Glossodoris cincta & 2 & - & - & - & - \\
Goniobranchus & 1 & - & - & - & - \\
geometricus & & - & 1 & - & - \\
Flabelina exoptata & - & 1 & - & - & - \\
Phyllidia ocellata & 1 & - & - & - & - \\
Phyllidiella varicose & 2 & - & - & - & - \\
Phyllidiella lizae & 1 & 1 & 2 & - & - \\
\hline Jumlah & 8 & $9,1 \%$ & $18,18 \%$ & - & - \\
\hline Persentase & $72,72 \%$ & & & &
\end{tabular}

Kehadiran 5 jenis substrat yang ditempati nudibranch di 3 lokasi, yaitu Nudifall, Makawide, dan Nudiritrit, di mana ada jenis substrat yang hanya ditempati oleh 1 jenis nudibranch, selanjutnya ada jenis nudibranch yang menempati (cooccur) "overlap" di satu substrat (Gambar 4). Dari 5 jenis substrat ini dapat dilihat bahwa hanya Hard coral dan Tunikata yang ditempati masing-masingnya satu spesies nudibranch. Terdapat satu spesies nudibranch pada substrat sponge dan dua spesies nudibranch yang terdapat pada substrat sponge dan DCA. Untuk substrat alga terdapat empat spesies dan dua spesies yang terdapat pada substrat alga dan DCA. Kemudian ada 8 spesies nudibranch yang hanya menempati substrat DCA (Gambar 1).

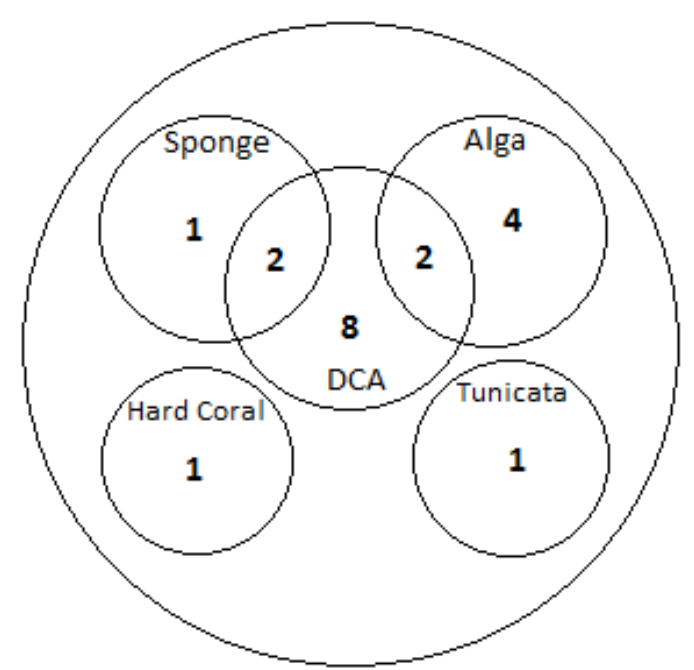

Gambar 1. Diagram Venn menunjukkan jenis nudibranch yang didapati pada substrat. Angka menunjukkan jumlah jenis. 
Tabel 6. Jenis nudibranch dalam beberapa substrat di Nudifall, Makawide, dan Nudiritrit

\begin{tabular}{|c|c|c|c|c|c|}
\hline \multirow[b]{2}{*}{ Spesies } & \multicolumn{5}{|c|}{ Substrat } \\
\hline & DCA & Sponge & Alga & $\begin{array}{l}\text { Hard } \\
\text { Coral }\end{array}$ & Tunikata \\
\hline Chromodoris annae & + & & + & & \\
\hline Chromodoris hamiltoni & & + & & & \\
\hline Chromodoris lochi & & & + & & \\
\hline Aegires villosus & & & + & & \\
\hline Jorunna funnebris & & & & + & \\
\hline Glossodoris cincta & + & & & & \\
\hline Goniobranchus fidelis & + & & & & \\
\hline Goniobranchus geometricus & + & & + & & \\
\hline Goniobranchus reticulatus & & & + & & \\
\hline Hypselodoris tryoni & + & & & & \\
\hline Halgerda batangas & + & & & & \\
\hline Nembrotha kubaryana & & & & & + \\
\hline Flabellina rubrolineata & + & & & & \\
\hline Flabellina exoptata & & & + & & \\
\hline Phyllidia elegans & + & & & & \\
\hline Phyllidia ocellata & + & + & & & \\
\hline Phyllidiella varicosa & + & + & & & \\
\hline Phyllidia coelestis & + & & & & \\
\hline Phyllidiella lizae & + & & & & \\
\hline
\end{tabular}

Dari tabel di atas dapat dilihat bahwa substrat DCA merupakan substrat yang overlap atau tumpang tindih dari beberapa jenis nudibranch. Perbedaan dan persamaan substrat antar jenis-jenis nudibranch ini dapat dikarenakan perilaku makannya. Menurut Behrens (2005) mengatakan bahwa nudibranch biasanya mengandalkan satu sumber makanan tergantung jenis dari nudibranch tersebut. Namun secara keseluruhan kelompok ini dapat memanfaatkan berbagai macam sumber makanan.
Berdasarkan komposisi spesies nudibranch yang ada, substrat juga bisa dibagi menjadi 8 kelompok (Gambar 2). Kelompok pertama terdiri dari Goniobranchus geometricus dan Chromodoris annae hal ini dikarenakan dua spesies ini didapati memiliki kesamaan substrat yaitu DCA dan Alga. Kelompok kedua yaitu Flabellina exoptata, Goniobranchus reticulatus, Aegires villosus dan Chromodoris lochi. Kelompok ini merupakan jenis yang didapati pada substrat alga, hal ini bisa dikarenakan perilaku makannya. Untuk kelompok tiga 
terdiri dari Phyllidia coelestis, Phyllidia elegans, Flabellina rubrolineata, Halgerda batangas, Hypselodoris tryoni, Goniobranchus fidelis dan Glossodoris cincta. Dari ke tujuh spesies ini didapati pada substrat yang sama yaitu DCA. Kelompok empat terdiri dari dua spesies yaitu Phyllidia varicosa dan Phyllidia ocellata. Dua spesies ini merupakan Nudibranch yang didapati pada dua jenis substrat yaitu DCA dan sponge. Kemudian untuk Chromodoris hamiltoni termasuk dalam kelompok ke lima yang didapati hanya pada substrat sponge. Kelompok enam hanya terdapat satu jenis saja yaitu Phyllidiella lizae yang terdiri dari lima individu dan semuanya ditemukan pada substrat DCA. Untuk kelompok tujuh dan delapan masing-masing hanya terdiri dari satu jenis substrat yaitu Jorunna funnebris substrat hard coral dan Nembrotha kubaryana substrat tunikata.
Nudibranch yang menempel pada substrat memanfaatkanya sebagai tempat berlindung, sumber makanan, dan sebagai tempat tinggal (Kaligis et al, 2018; Ompi et al, 2019). Jenis-jenis nudibranch memanfaatkan keragaman warna tubuhnya menyerupai substrat untuk mengelabui dari pemangsaan predator, misalnya dengan menempati substrat DCA, sponge, alga, hard coral dan tunikata dalam penelitian ini.

Nudibranch dikenal sebagai biota beracun (Fisch et al, 2017), di mana tingkat racun biota ini dapat berubah-ubah disebabkan oleh perubahan pola makan, misalnya dari jenis makanan yang satu ke jenis makanan yang lain. Dalam penelitian ini dapat dilihat ada jenis menempati karang, tetapi juga ada yang menempati sponge ataupun alga. Ragam substrat yang ditempati ini dapat disebabkan oleh perubahan pola makan. 


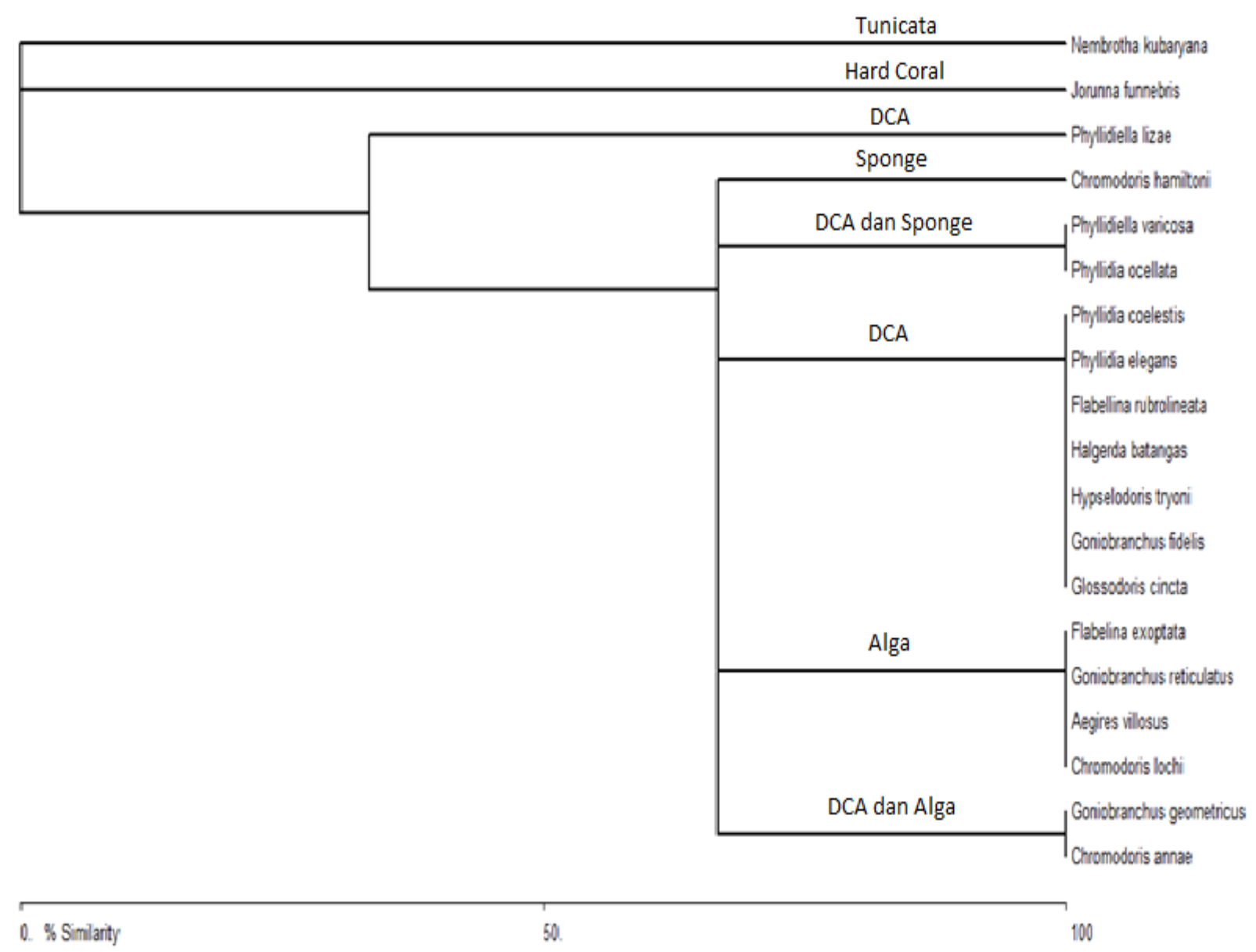

Gambar 5. Dendogram kelompok nudibranch yang memiliki kesamaan substrat

Kesamaan substrat yang didapati terbagi dalam 8 kelompok yaitu kelompok pertama 2 spesies nudibranch pada

\section{Kesimpulan}

Nudibranch yang ditemukan di ketiga lokasi dalam penelitian ini ada 19 jenis. Nudibranch yang ditemukan di Selat Lembeh memiliki kebergamaan substrat dari masing-masing jenisnya. Substrat yang dominan ditempati oleh nudibranch adalah dead coral with alga. Walaupun terdapat substrat lain yaitu alga, sponge, tunikata dan hard coral. Hal ini dapat memiliki keterkaitan dengan kebiasaan makan dari masing-masing jenis nudibranch. substrat DCA dan alga. Kelompok dua terdiri dari 3 spesies nudibranch pada substrat alga. Kelompok tiga terdiri dari 7 spesies nudibranch pada substrat DCA. Kelompok empat 2 spesies nudibranch pada substrat DCA dan alga. Kelompok kelima 1 spesies pada substrat sponge. Kelompok enam yaitu 5 individu dari 1 spesies nudibranch pada substrat DCA. Kelompok tujuh 1 jenis nudibranch pada substrat hard coral dan kelompok delapan 1 jenis nudibranch pada substrat tunikata.

\section{Daftar Pustaka}


Behrens. D. W. 2005. Nudibranch Behavior. NEW WORLD PUBLICATION, INC. Jacksonville, Flodira U.S.A

Bell, J.D. \& Galzin, R. 1984. "Influence of Coral Cover on Coral-Reef Fish Communities". Marine Ecology Progress Series 15: 265-274.

Chavanich. S, Viyakarn. V, Sanpanich. K, \& Harris L.G. 2013. Diversity and occurence of nudibranch in Thailand. Marine Biodiversity 43: 31-36

Dai. C.F, Lance. L, Stewart, Richard. A, Cooper, \& Sprunk. H.J. 1992. Distribution of Substrates and Macrobenthos at depths between 35 and $120 \mathrm{M}$ in Southern Taiwan. Acta oceanographica Taiwanica No.28; pp 1-18 .

Debelius, H. 2004. Nudibranch and Sea Snails IndoPacific Field Guide. IKAN-Unterwasserarchiv, Frankfurt: $320 \mathrm{pp}$.

Fisch K., Hertzer C., Bohringer N., Wuisan Z. G., Schillo D., Bara R., Kaligis F., Wagele H., Konirg G.M., \& Schaberle T. 2017. The Potential Heterobranche Found Around Bunaken Island for the Production of bioactive compounds. Marine drugs $15: 1-45$

Greene. H.G, O'Connell. V, Brylinsky. C.K, \& Reynolds. J.R. 2008. Marine Benthic Habitat Classification : What's Best for Alaska ?. Marine Habitat Mapping Technology for Alaska.

Holland, J. S. 2008. Warna Warni Kehidupan. NG Indonesia edisi Juni 2008: 80-83.

Kaligis. F, Eisenbarth J.H, Schillo. D, Dialao. J, Scharberle. T.F, Bohringer . N, Bara. R, Reumschussel . S, Konig. G.M, \&
Wagele. H. 2018. Second Survey of heterbranch seaslugs (Mollusca, Gastropoda, Heterobranchia) from Bunaken National Park, North Sulawesi, Indonesia. Marine Biodiversity Record 11:2.

Krebs, 1978. Ecology. The Experimental Analysis of Distribution and Abundance. Trhid Edition Harper and Row Distribution, New York.

Odum, E. P. 1971. Fundamentals of ecology. W.B. Philadelphia: Sounders Company Ltd.

Ompi. M, Lumoindong. F, Undap. N, Papu. Adelfia, \& Wagele. H. 2019. Monitoring marine Heterobranchia in Lembeh Strait, Nort Sulawesi (Indonesia), in a changing environment. AACL Bioflux Vol 12 , Issue 2.

Purba. A, Kusen J. D, \& Mamangkey, N. G. F. 2013. Struktur Komunitas Gastropoda Nudibranchia Di Perairan Desa Waleo (Laut Maluku) Dan Perairan Desa Kalasey (Teluk Manado, Laut Sulawesi). Journal Aquatic Science \& Management. Vol. 1, No. 1, 21-25. 